\title{
COMPARISON OF SUBCOSTAL TRANSVERSUS ABDOMINIS PLANE BLOCK WITH PORT SITE INFILTRATION OF LOCAL ANAESTHESIA IN LAPAROSCOPIC CHOLECYSTECTOMY
}

\author{
Kaukab Majeed, Nazish Shaukat*, Muhammad Ali Muazzam**, Usman Khalid, Junaid Zafar, Sajid*** \\ Pak Emirates Military Hospital/National University of Medical Sciences (NUMS) Rawalpindi Pakistan, *Armed Forces Institute of Ophthalmology/National \\ University of Medical Sciences (NUMS) Rawalpindi Pakistan, ${ }^{* *}$ Combined Military Hospital Quetta/National University of Medical Sciences (NUMS) Pakistan, \\ ${ }^{* * *}$ Combined Military Hospital Skardu/National University of Medical Sciences (NUMS) Pakistan
}

\begin{abstract}
Objective: To compare the efficacy of ultrasound guided subcostaltransversus abdominis plane block and port site infiltration of local anaesthesia in patients undergoing laparoscopic cholecystectomy.

Study Design: Comparative cross sectional study.

Place and Duration of Study: Anesthesiology department, Pak Emirates Military Hospital, Rawalpindi, from Jan to Jun 2019. Methodology: A sample size of 62 patients calculated by World Health Organization calculator were randomized in a doubleblind study to undergo Sub costal transversus abdominis plane block or port site infiltration by non-probability, consecutive sampling into two equal groups. Group A received sub costal transversus abdominis plane block and group B local anaesthetic. Postoperative pain perception was measured using visual analogue scale.

Results: The mean age of patients in group A was $33.39 \pm 8.91$ years and in group B was $33.77 \pm 8.45$ years. Out of 62 patients $38(61.29 \%)$ were males and $24(38.71 \%)$ were females. Mean pain score in group A (ultrasound guided sub costal transversus abdominis plane block) was $1.61 \pm 0.91$ while in group B (port site infiltration of local anaesthetic) was $3.61 \pm 1.05(p$-value 0.0001).

Conclusion: The mean pain score was less following use of ultrasound guided sub costal transversus abdominis plane block in patients undergoing laparoscopic cholecystectomy as compared to port site infiltration of local anaesthesia.
\end{abstract}

Keywords: Regional anaesthesia, Subcostal block, Transverse adominis plane block.

\footnotetext{
This is an Open Access article distributed under the terms of the Creative Commons Attribution License (http://creativecommons.org/licenses/by/4.0), which permits unrestricted use, distribution, and reproduction in any medium, provided the original work is properly cited.
}

\section{INTRODUCTION}

Laparoscopic cholecystectomy (LC) was initially performed by Philippe Mouret in 1987. It is considered as the treatment of choice for cholelithiasis ${ }^{1}$. It is one of the most frequently performed surgery in USA. LC leads to early recoveryand is associated with shorter hospitalization period ${ }^{2}$. Laparoscopic cholecystectomy leads to moderate pain in early postoperative period necessitating the use of multimodal analgesic approach for it such as the use of opioid analgesics and local anaesthetics at port site ${ }^{3}$.

Ultrasound guided (US) transversus abdominis plane (TAP) blockade, a recent advancement, for post surgical pain relief. Moreover, subcostal method, which is modification of TAP blockadewhich produces satisfactory supraumbilical pain relief in early postoperative period. TAP blockade involves administration of analgesia at Petit triangle ${ }^{11}$.

It is observed according to some studies that US guided subcostal TAP blockade provides enhancedanalgesia due to lesser pain scores and decreased opioid requirement after laparoscopic cholecystectomy compared to port site infiltration ${ }^{6}$, also it reduces

Correspondence: Dr Muhammad Ali Muazzam, Department of Surgery, Combined Military Hospital Quetta Pakistan

Received: 09 Oct 2019; revised received: 18 Dec 2019; accepted: 23 Dec 2019 rescue analgesic requirement ${ }^{7}$, and prolongs the time for first pain-relieving demand in early post-surgical time $^{8}$. The cost-effectiveness of anaesthesia has also been found to be better in patients receiving subcostal blockadein patients undergoing $\mathrm{LC}^{9}$. On the contrary, some studies say that there is no difference in effectiveness of both, measured in terms of 24 hour morphine requirement.

In a recent study pertaining to my research, mean analgesic (fentanyl) requirement in US guided-subcostal TAP blockade versus regionalinfiltration group after LC was $33.16 \mathrm{mcg}$ (SD 54.17) and $86.90 \mathrm{mcg}$ (SD 73.97) respectively ${ }^{10}$.

Subcostal TAP blockade has recently been used for post surgical analgesia after LC in our setup. Since there is difference in the results of different studies, some saying subcostal TAP block is superior but according to some no variance between subcostal TAP blockade and local analgesia, thus, the rationale of our study was to measure the efficacy of subcostal TAP block versus conventional port site infiltration of local anaesthetic in reduction of postsurgical pain.

\section{METHODOLOGY}

This comparative cross sectional study was conducted in department of Anaesthesiology, of Pak 
Emirates Military Hospital, Rawalpindi, from January to June 2019. Study was initiated after approval from hospital research ethics committee. Sample size was determined using WHO sample size calculatorwith following assumptions: Power of test $80 \%$, Significance level of $5 \%$, test value of the population mean= 86.9010, Anticipated population mean $=33.1610$, Mean pain score in US guided subcostal transversus abdominis plane blockade was mean \pm SD $3.67 \pm 2.20$ while in port site infiltration of local anaesthetic was mean \pm SD $3.00 \pm 2.17$. ( $p$-value 0.31). Mean sample size $n=31$ patients in each group, total $=62$ patients. Sampling technique was non-probability, consecutive sampling.

A total of 62 patients of both gender with cholelithiasis, ASA status I and II, BMI $<30$ and normal coagulation profile were included in the study. Patient with acute cholecystitis \& pancreatic cholangitis, previous open upper abdominal surgery, unfit for regional anaesthesia and unfit for pneumoperitoneum were excluded.

Informed written consent was obtained after explaining purpose of study and advantages and disadvantages of each technique used. Participants were designated from laparoscopic surgeon outpatient department and pre-anaesthetic clinic. They were randomized in a double-blind way to undergo Subcostal TAP block or port site infiltration by non-probability, consecutive sampling into two equal groups. The patients in Group A: subcostalTAP block with $20 \mathrm{G}$ spinal needle with $0.25 \%$ bupivacaine $10 \mathrm{ml}$ bilateral were given under US guidance. Group B: port site infiltration of $10 \mathrm{ml}$ of $0.5 \%$ bupivacaine.

General anaesthesia was given by classified anaesthetist and a standardized general anaesthetic regime was employed, consisting of propofol (2.5 $\mathrm{mg} / \mathrm{kg})$, and atracurium besylate $(0.5 \mathrm{mg} / \mathrm{kg})$, maintenance by isoflurane (2\%-3\%), with intraoperative opioid analgesia of nalbuphine $(0.1 \mathrm{mg} / \mathrm{kg})$.

All patients will undergo the standard laparoscopic cholecystectomy performed by a laparoscopic surgeon with at least one-year experience of laparoscopic surgeries. Three subcostal and one periumbilical port sites were employed in all cases. The volume and dose of local anaesthetic did not differ between the groups. The subcostal TAP block was performed by an anaesthetist whereas port-site infiltration was performed by the surgeon at the end of surgery.

Postoperative pain perception was measured using visual analogue scale at different hours, by welltrained differenthouse officers, who were kept blind regarding the intervention. Visual analogue score was measured at 0 hours (upon receiving patient in recovery), 2 hours and 4 hours after surgery. Average of three readings was calculated as per operational definition. This information along with age, gender, duration of surgery, status was noted.

Data was analysed using SPSS-23. Quantitative variables were analysed as mean and standard deviation. Group A (Subcostal TAP block) and group B (port site infiltration) were compared for mean post-operative pain by applying independent sample t-test. For normal data t-test was applied to compare mean pain scores between groups at different points of time. For non-normal data Mann-Whitney $U$ test was applied to compare mean pain score. A $p$-value $\leq 0.05$ was considered significant.

\section{RESULTS}

A sample size of 62 patients calculated by $\mathrm{WHO}$ calculator of year requiring laparoscopic cholecystectomy of both genderswere randomized in a doubleblind study to undergo Subcostal TAP block or port site infiltration by non-probability, consecutive sampling into two equal groups. Mean age of patients was

Table-I: Comparison of pain score with respect to age groups.

\begin{tabular}{|c|c|c|c|}
\hline \multirow{2}{*}{$\begin{array}{l}\text { Age of } \\
\text { Patients } \\
\text { (years) }\end{array}$} & Group A $(n=31)$ & Group B $(n=31)$ & \multirow[b]{2}{*}{$\begin{array}{c}p \text { - } \\
\text { value }\end{array}$} \\
\hline & $\begin{array}{l}\text { Pain Score } \\
\text { Mean } \pm \text { SD }\end{array}$ & $\begin{array}{l}\text { Pain Score } \\
\text { Mean } \pm \text { SD }\end{array}$ & \\
\hline $20-35$ & $1.84 \pm 1.07$ & $3.69 \pm 1.14$ & 0.0001 \\
\hline $36-50$ & $1.75 \pm 0.62$ & $3.53 \pm 0.99$ & 0.0001 \\
\hline \multicolumn{4}{|c|}{$\begin{array}{l}\text { Table-II: Comparison of pain score with respect to } \\
\text { gender. }\end{array}$} \\
\hline \multirow[b]{2}{*}{ Gender } & Group A $(n=31)$ & Group B $(n=31)$ & \multirow[b]{2}{*}{$\begin{array}{c}p- \\
\text { value }\end{array}$} \\
\hline & $\begin{array}{l}\text { Pain Score } \\
\text { Mean } \pm \text { SD }\end{array}$ & $\begin{array}{l}\text { Pain Score } \\
\text { Mean } \pm \text { SD }\end{array}$ & \\
\hline Male & $1.83 \pm 1.03$ & $4.00 \pm 1.13$ & 0.0001 \\
\hline Female & $1.79 \pm 0.86$ & $3.37 \pm 0.96$ & 0.0001 \\
\hline
\end{tabular}

Table-III: Comparison of pain score with respect to duration of operation.

\begin{tabular}{l|c|c|c}
\hline $\begin{array}{l}\text { Duration } \\
\text { of }\end{array}$ & $\begin{array}{c}\text { Group A } \\
(\mathbf{n}=31)\end{array}$ & Group B (n=31) & \\
\cline { 2 - 3 } $\begin{array}{l}\text { Operation } \\
\text { (minutes) }\end{array}$ & $\begin{array}{c}\text { Pain Score } \\
\text { Mean } \pm \text { SD }\end{array}$ & $\begin{array}{c}\text { Pain Score } \\
\text { Mean } \pm \text { SD }\end{array}$ & value \\
\hline$\leq 30$ & $1.73 \pm 1.03$ & $3.38 \pm 1.02$ & 0.0001 \\
\hline$>30$ & $1.88 \pm 0.81$ & $3.87 \pm 1.06$ & 0.0001 \\
\hline
\end{tabular}

Table-IV: Comparison of pain score with respect to body mass index.

\begin{tabular}{|c|c|c|c|}
\hline \multirow[b]{2}{*}{$\begin{array}{l}\text { BMI } \\
\left(\mathrm{kg} / \mathrm{m}^{2}\right)\end{array}$} & Group A $(n=31)$ & Group B $(n=31)$ & \multirow[b]{2}{*}{$\begin{array}{c}p- \\
\text { value }\end{array}$} \\
\hline & $\begin{array}{l}\text { Pain Score } \\
\text { Mean } \pm \text { SD }\end{array}$ & $\begin{array}{l}\text { Pain Score } \\
\text { Mean } \pm \text { SD }\end{array}$ & \\
\hline$\leq 27$ & $1.95 \pm 0.91$ & $3.67 \pm 0.84$ & 0.0001 \\
\hline $28-30$ & $1.58 \pm 0.90$ & $3.54 \pm 1.33$ & 0.0001 \\
\hline
\end{tabular}


$33.56 \pm 8.61$ years. Mean age of participants in group A was $33.39 \pm 8.91$ years and in group B was $33.77 \pm 8.45$ years. Most of the patients $35(56.45 \%)$ were between 20-35 years of age. Out of 62 patients $38(61.29 \%)$ were males and $24(38.71 \%)$ were females with male to female ratio of 1.6:1.

Mean pain score in Group A (US guided subcostal transversus abdominis plane blockade) was Mean \pm SD $1.61 \pm 0.91$ while in group B (port site infiltration of local anaesthetic) was Mean \pm SD $3.61 \pm 1.05$. ( $p$-value 0.0001). Comparison of mean pain score in relation to age groups, gender, duration of surgery and BMI were given in (table I-IV).

\section{DISCUSSION}

Laparoscopic cholecystectomy has become more popular due to early recovery and shorter hospitalization $^{2}$. LC is accompanied with moderate pain in early postoperative period necessitating the use of multimodal analgesic approach for it such as the use of opioid analgesics and infiltration of regional anaesthetics at port site ${ }^{3}$.

Subcostal TAP blockade is a frequently used technique after various abdominal surgeries ${ }^{12}$. Rafi et al ${ }^{11}$, in 2001 initially substantiated it to be effective in decreasing the opioid usewhile performing the abdominal field block via the lumbar triangle on >200 patients without any untoward sequelae for 2 years.

Hebbard et al13, in 2007 explained that US guided subcostal technique can provide pain relief in upper as well as lower abdominal surgeries. Additionally lower complication rate was reported due to use of ultrasound technology.

Suseela et al ${ }^{14}$, in 2018 explained time to first analgesic (Mean \pm SD) in group I and group T was 292.7 \pm 67.03 and $510.3 \pm 154.55 \mathrm{~min}$ and mean tramadol required was $141.8 \pm 60.01 \mathrm{mg}$ and $48.69 \pm 36.14 \mathrm{mg}$, $(p=0.001)$ for both subcostal TAP block and port site infiltration bilaterally respectively.

Outcomes of our study validate that the mean pain score following use of US guided subcostal TAP blockade supplemented byport sitepermeation of local anaesthetic in patients undergoing LC was less at rest as well as on activity. Mean pain score in group A (US guided subcostal transversus abdominis plane blockade) was $1.61 \pm 0.91$ while in group B (port site infiltration of regionalanaesthesia) was $3.61 \pm 1.05$ ( $p$-value $<0.01)$.

In a recent study by Kadam et al ${ }^{10}$, in 2016 pertaining to our research, mean analgesic (fentanyl) req- uirement in US guided TAP blockade versus local infiltration group after LC was $33.16 \mathrm{mcg}(\mathrm{SD} \pm 54.17)$ and $86.90 \mathrm{mcg}(\mathrm{SD} \pm 73.97)$ respectively.

On the contrary, study by Kokulu et al ${ }^{9}$, in 2014 says that there is no difference in effectiveness of both, measured in terms of 24-hour morphine requirement that is $34.57 \pm 14.64 \mathrm{mg}$ in TAP set and $32.76 \pm 14.34 \mathrm{mg}$ in regional infiltration set.

El-Dawlatly et al15, in 2009 reported lesser usage of opioids (8.6 $\mu \mathrm{g}$ vs $23 \mu \mathrm{g} ; p<0.01)$, and of morphine within 24 hours $(10.5 \mathrm{mg}$ vs $22.8 \mathrm{mg}$; $p<0.05)$ in TAP group.

On the other hand, Ortiz et al ${ }^{16}$ in 2016 reported statisticallysignificant difference in postsurgical pain and anaesthesiause in patients who were given TAP blockade, in comparison to port-site regional infiltration of analgesia. Khan et al18, in 2018 claimed 100\% result while comparing subcostal TAP group and posterior TAP group.

Baral et al17, in 2019 revealed the 24 hours' opioids consumption was significantly less $(125 \mathrm{mg} \pm 25.42$ versus $175 \mathrm{mg} \pm 25.42, p<0.001$ ) in Subcostal TAP block group. This difference may be due to difference in study method and the type of blockade such as TAP, blind, subcostal or posterior method. Variation in timing of administration, drug or dose may affect the outcomes.

\section{CONCLUSION}

Analgesia was longer following use of subcostal TAP block in patients undergoing laparoscopic cholecystectomy as compared to port site infiltration of local anaesthetic. So, we recommend subcostal TAP block may be used in patients undergoing laparoscopic cho-lecystectomy in order to reduce the morbidity of patients.

\section{CONFLICT OF INTEREST}

This study has no conflict of interest to be declared by any author.

\section{REFERENCES}

1. Liu D, Guan F, Wang B. Combined usage with intra-peritoneal and incisional ropivacaine redness pain severity after laparoscopic cholecystectomy. Int J Clin Exp Med 2015; 8(12): 22460-68.

2. Chong JU, Lee JH, Yoon YC, Kwon KH, Cho JY, Kim SJ, et al. Influencing factors on postoperative hospital stay after laparoscopic cholecystectomy. Korean J Hepatobiliary Pancreat Surg. 2016; 20(1): 12-16.

3. Mitra S, Khandelwal P, Roberts K, Kumar S, Vadivelu N. Pain relief in laparoscopic cholecystectomy-a review of the current options. Pain Pract 2012; 12(6): 485-96.

4. Saxena R, Joshi S, Srivastava K, Tiwari S, Sharma N, Valecha UK. Comparative study of ultrasound-guided abdominal field blocks 
versus port infiltration in laparoscopic cholecystectomies for post-operative pain relief. Ind J Anaesth 2016; 60(8): 578-83.

5. Mukherjee A, Guhabiswas R, Kshirsagar S, Rupert E. Ultrasound guided oblique subcostal transversus abdominis plane block: An observational study on a new and promising analgesic technique. Ind J Anaesth 2016; 60(4): 284-86.

6. Tolchard S, Davies R, Martindale S. Efficacy of the subcostal transversus abdominis plane block in laparoscopic cholecystectomy: Comparison with conventional port-site infiltration. J Anaesthe-siol Clin Pharmacol 2012; 28(3): 339-43.

7. Petersen P, Stjernholm PKV, Torup H, Hansen E, Mitchell A, Moeller A. The beneficial effect of transversus abdominis plane block after laparoscopic cholecystectomy in day-case surgery: A randomized clinical trial. Anesth Analg 2012; 115(3): 527-33.

8. Saliminia A, Azimaraghi O, Babayipour S, Ardavan K, Movafegh A. Efficacy of transverse abdominis plane block in reduction of postoperation pain in laparoscopic cholecystectomy. Acta Anaesthesiol Taiwan 2015; 53(4): 119-22.

9. Kokulu S, Baki E, Kaçar E, Bal A, Şenay H, Ustün K, et al. Effect of transversus abdominis plane block on cost of laparoscopic cholecystectomy. Anaesth Med Sci Monit 2014; 20(1): 2783-87.

10. Kadam VR, Howell S, Kadam V. Evaluation of postoperative pain scores following ultrasound guided transversus abdominis plane block versus local infiltration following day surgery laparoscopic cholecystectomy-retrospective study. J Anaesthesiol Clin Pharmacol 2016; 32(1): 80-83.

11. Rafi AN. Abdominal field block: a new approach via the lumbar triangle. Anaesth 2001; 56(10): 1024-26.

12. Shibata Y, Sato Y, Fujiwara Y, Komatsu T. Transversus abdominis plane block. Anesth Analg 2007; 105(3): 883-85.

13. Hebbard P, Fujiwara Y, Shibata Y, Royse C. Ultrasound-guided transversus abdominis plane (TAP) block. Anaesth Intensive Care 2007; 35(4): 616-17.

14. Suseela I, Anandan K, Aravind A, Kaniyil S. Comparison of ultrasound-guided bilateral subcostal transversus abdominis plane block and port-site infiltration with bupivacaine in laparoscopic cholecystectomy. Ind J Anaesth 2018; 62(7): 497-1.

15. El-Dawlatly AA, Turkistani A, Kettner SC, Machata AM, Delvi MB, Thallaj A, et al. Ultrasound-guided transversus abdominis plane block: description of a new technique and comparison with conventional systemic analgesia during laparoscopic cholecystectomy. Br J Anaesth 2009; 102(6): 763-67.

16. Ortiz J, Suliburk JW, Wu K, Bailard NS, Mason C, Minard CG, et al. Bilateral transversus abdominis plane block does not decrease postoperative pain after laparoscopic cholecystectomy when compared with local anaesthetic infiltration of trocar insertion sites. Reg Anesth Pain Med 2016; 37(2): 188-92.

17. Baral B, Poudel PR. Comparison of analgesic efficacy of ultrasound guided subcostal transversus abdominis plane block with port site infiltration following laparoscopic cholecystectomy. J Nepal Health Res Counc 2019; 16(41): 457-61.

18. Khan KK, Khan RI. Analgesic effect of bilateral subcostal tap block after laparoscopic cholecystectomy. J Ayub Med Coll Abbottabad 2018; 30(1): 12-15. 